\title{
MR-Guided Focused Ultrasound* in Fibroid Treatment - Results of the 3rd Radiological-Gynecological Expert Meeting
}

\author{
Magnetresonanzgeführter fokussierter Ultraschall \\ zur Myombehandlung - Ergebnisse des 3. radiologisch- \\ gynäkologischen Expertentreffens
}

Authors

Matthias David', Matthias Matzko²

\author{
Affiliation \\ 1 Charité Universitätsmedizin Berlin, Campus Virchow- \\ Klinikum, Klinik für Gynäkologie, Berlin, Germany \\ 2 Helios Amper-Klinikum Dachau, Diagnostische und \\ interventionelle Radiologie, Dachau, Germany \\ Bibliography \\ DOI https://doi.org/10.1055/s-0043-108994 \\ Published online: 2017 | Fortschr Röntgenstr 2017; 189: \\ 515-518 @ Georg Thieme Verlag KG, Stuttgart · New York, \\ ISSN 1438-9029
}

Correspondence

Prof. Dr. Matthias David

Charité Universitätsmedizin Berlin, Campus Virchow-

Klinikum, Klinik für Gynäkologie, Augustenburger Platz 1,

Berlin, Germany

matthias.david@charite.de

Dr. Matthias Matzko

Helios Amper-Klinikum Dachau, Diagnostische und

interventionelle Radiologie, Dachau, Germany

vorzimmer-radiologie.dachau@helios-kliniken.de

\section{Introduction}

Fibroid treatment with MR-guided focused ultrasound (MRgFUS; syn.: HIFU = high-intensity focused ultrasound) is a thermoablative method in which the tissue to be treated is heated by focused ultrasound in single small volume increments (sonifications, syn: sonications) under constant MRI control until complete denaturation of the planned fibroid volume is achieved. After thermoablation, imaging showed a lack of contrast enhancement of the treated tissue (NPV = non-perfused volume).

MRgFUS is organ-preserving and noninvasive and can be performed on an outpatient basis.

The treatment method is offered only by a few specialized centers.

The goal of MRgFUS treatment is to reduce or eliminate fibroid-related symptoms in affected women. A reduction in fibroid size can be achieved with ultrasound treatment. Complete fibroid regression is not to be expected and is also not the goal of the treatment.

The disciplines of gynecology and radiology agree that the indication for the treatment of uterine fibroids should be determined by a gynecologist following examination and counseling of the patient. Comprehensive patient counseling regarding the

* To be differentiated from non-MR-guided focused ultrasound. treatment options in symptomatic uterine fibroids should include medication, surgery, and the two non-surgical treatment options uterine artery embolization (UAE) and MRgFUS. The decision for or against a treatment alternative should be made under consideration of the patient's wishes and with knowledge of other treatment options, the chance of success, limitations, typical side effects, and possible complications (informed consent).

MRgFUS treatment provides a treatment method for patients with fibroid-related symptoms and allows further treatment individualization for uterine fibroids in Germany, Austria, and Switzerland.

\section{Goal of the consensus meeting}

The intention of this third consensus meeting was to evaluate and categorize MRgFUS in the fibroid treatment spectrum. The 12 participants of the radiological-gynecological expert meeting came to a consensus following thorough discussion with evaluation of the current literature ${ }^{1}$ and their own experiences.

The group of experts was aware that the possibilities and limitations of a radiological treatment method was being discussed together with gynecology specialists who do not actually perform 
the procedure but have expertise and experience with the diagnosis and medication-based and surgical treatment of diseases of the female genitals.

The expert group comprised of 4 radiologists and 8 gynecologists that met on January 14, 2017 in Berlin for the third radiological-gynecological consensus meeting regarding MRgFUS treatment also included gynecologists from Switzerland.

Following extensive and at times also controversial discussion, the group agreed in consensus upon the following recommendations. The consensus paper is supported by the gynecologists and radiologists listed at the end of the article. The paper reflects the current state of knowledge.

\section{Structural requirements for performing MRgFUS treatment}

MRgFUS should only be performed at hospitals with the necessary expertise and experience. This also includes the conservative and surgical management of side effects and complications. Moreover, there should be options for introducing postinterventional pain therapy.

\section{Examinations required prior to MRgFUS treatment}

Treatment decisions are based on gynecological examination including vaginal and/or abdominal ultrasound (depending on the size of the uterine fibroid). An MRI scan with contrast agent ideally in prone position must be acquired for planning purposes. The contrast-enhanced image helps to assess whether and to what degree the fibroid is perfused.

Prior to every MRgFUS procedure, the indication for hysteroscopy and fractionated abrasion should be examined as a function of bleeding pattern and endometrium thickness and structure. A cytological smear of the cervix uteri with a normal result needs to have been performed within the last 12 months.

During the informed consent discussion prior to MRgFUS, the patient should also be informed of the lack of preinterventional histological confirmation, as in all other organ-preserving fibroid treatment methods.

\section{Indications for MRgFUS treatment}

A symptomatic uterine fibroid with an anatomical position allowing safe access for MRgFUS is an indication for MRgFUS treatment. Treatment is complicated by the presence of more than five fibroids. In the case of fibroids with a diameter of more than $10 \mathrm{~cm}$, the indication for MRgFUS treatment should be carefully considered due to the large fibroid volume and the associated long treatment time.

MRgFUS represents an alternative to surgical and medicationbased methods such as UAE. Treatment decisions should be based on the treatment objective and the wishes of the patient. If tech- nically feasible, MRgFUS is a good option for patients desiring the least invasive treatment possible.

\section{Success criteria for MRgFUS treatment}

The goal of treatment with focused ultrasound is to achieve the greatest possible NPV (= non-perfused volume).

The improvement or elimination of fibroid-related symptoms is viewed as treatment success following MRgFUS treatment. A volume reduction is desired but is considered a secondary treatment goal.

\section{Contraindications for MRgFUS treatment}

- Primarily Malignancy (absolute)

- Pregnancy (absolute)

- Acute inflammatory process (absolute)

- Subserosal pedunculated fibroids (absolute)

- Submucosal fibroids type 0 and I (relative; absolute in case of a desire to have children)

- Insufficient acoustic window for treatment (e. g. bowel overlying the fibroid) (absolute)

- More than 5 fibroids (relative, decided on a case-by-case basis)

- Uterine fibroids with a diameter greater than $10 \mathrm{~cm}$ (relative, decided on a case-by-case basis)

- Large scars in the acoustic window (relative)

- Fibroid positioned near the os sacrum (relative)

- General contraindications to MR contrast agents (relative)

- Relative and absolute MRI contraindications

Ulipristal acetate can result in increased perfusion of fibroids; consequently the evaluation of the feasibility of MRgFUS treatment and the actual treatment can be negatively affected.

In the case of suspicion of a malignancy of the uterus, MRgFUS is absolutely contraindicated.

\section{MRgFUS treatment in patients with a desire to have children}

There is no published prospective data regarding women who wish to have children and have been treated with MRgFUS/HIFU. Therefore, MRgFUS/HIF treatment cannot be recommended prior to a planned pregnancy. However, if a patient wants to become pregnant after MRgFUS/HIFU treatment, a minimum wait time of approximately 6 months between fibroid treatment with MRgFUS and conception should probably be observed.

\section{Side effects/complications of MRgFUS treatment}

Relevant side effects and complications during and after MRgFUS treatment are rare:

- Pain 
- Skin burns

- Inflammation of the subcutaneous fatty tissue and the musculature of the abdominal wall

- Paresthesia of the leg due to nerve irritation or damage

- Deep vein thrombosis (very rare)

- Intestinal perforation (extremely rare)

In addition to increased and/or irregular bleeding within three months after treatment, fibroid treatment with MRgFUS can result in discharge of (necrotic) fibroid material in terms of a "fibroid in the nascent state" that is unpleasant and painful for the patient. Uterus-preserving ablation performed via the vagina possibly also in combination with surgical hysteroscopy is also possible here. Perioperative antibiotic prophylaxis is recommended in these cases.

\section{Follow-up after MRgFUS treatment}

Follow-up by a specialist after MRgFUS is recommended. Imaging methods are helpful (e.g. ultrasound in connection with Doppler ultrasound, MRI). If treatment is not successful (no improvement in symptoms and/or increase in fibroid size) or in the case of pathologies on imaging (increase in size of fibroid(s) or uterus), further diagnostic workup is required.

\section{Future}

The recommendations regarding MRgFUS treatment of fibroids are to be revised in approximately two years under consideration of the data and experiences available at that time.

\section{Appendix}

\section{Participants in the consensus meeting 2017}

Prof. Dr. med. Michael Bohlmann/ Mannheim

Dr. med. Alexander Burges/ Munich

Prof. Dr. med. Matthias David/ Berlin

Prof. Dr. med. Markus Düx/ Frankfurt a.M.

Prof. Dr. med. Dr. phil. Dr. h. c. mult. Andreas D. Ebert/ Berlin

Prof. Dr. med. Peyman Hadji/ Frankfurt a.M.

Dr. med. Thomas Hess/ Winterthur (CH)

PD Dr. med. Peter Hunold/ Lübeck

Dr. med. Hans-Christian Kolberg/ Bottrop

Dr. med. Matthias Matzko/ Dachau

PD Dr. med. Vera Schreiter/ Berlin

Prof. Dr. med. Uwe Ulrich/ Berlin

\section{Participating societies and working groups:}

AGE, Arbeitsgemeinschaft Gynäkologische Endoskopie der DGGG AG URZ, Arbeitsgemeinschaft Universitärer Reproduktionsmedizinischer Zentren der DGGG

Berufsverband der Frauenärzte (BVF)

DeGIR, Deutsche Gesellschaft für Interventionelle Radiologie und minimal-invasive Therapie
DGGEF, Arbeitsgemeinschaft Gynäkologische Endokrinologie und Fortpflanzungsmedizin e. V.

DGGG, Deutsche Gesellschaft für Gynäkologie und Geburtshilfe DRG, Deutsche Röntgengesellschaft

SGGG, Schweizerische Gesellschaft für Gynäkologie und Geburtshilfe

\section{References to relevant publications}

1. Bohlmann MK, Hoellen F, Hunold P, David M. High-Intensity Focused Ultrasound Ablation of Uterine Fibroids - Potential Impact on Fertility and Pregnancy Outcome. Geburtshilfe Frauenheilkd 2014; 74: 139 - 145.

2. Clark NA et al. Reproductive impact of MRI-guided focused ultrasound surgery for fibroids: a systematic review of the evidence. Curr Opin Obstet Gynecol 2014; 26: 151 - 161 https://www.ncbi.nlm.nih.gov/pmc/articles/PMC4137 489/ pdf/nihms-618 873.pdf

3. Denschlag D, Thiel FC, Ackermann S, Harter P, Juhasz-Boess I, Mallmann P, Strauss HG, Ulrich U, Horn LC, Schmidt D, Vordermark D, Vogl T, Reichardt P, Gaß P, Gebhardt M, Beckmann MW. Uterine Sarkome. Leitlinie der DGGG (S2k-Level, AWMF-Registernummer 015/074, August 2015). Geburtsh Frauenheilk 2015; 75; e3 DOI: 10.1055/s-0035-1558288

4. DGGG-Statement. Stellungnahme für die Einschätzung zur Erprobung der Magnetresonanztomografie-gesteuerten hochfokussierten Ultraschalltherapie zur Behandlung des Uterusmyoms (MRgFUS-TUF)“ http://www.dggg.de/fileadmin/documents/stellungnahmen/aktuell/2016/225_Stellungnahme_zur_MRT_US-Therapie_zur_Behandl_des_Uterusmyoms.pdf (Januar 2016)

5. Focused Ultrasound Fondation 2016 (Statusbericht) „State of the field“: http://www.fusfoundation.org/newsletterarchive/1738-focus-feature-2016-state-of-the-field-report

6. G-BA-Beschluss (Dezember 2016) betreffend „ErprobungsRichtlinie zur Behandlung von Uterusmyomen mittels MRgFUS“: https://www.g-ba.de/institution/presse/pressemitteilungen/657/

7. Jacoby VL et al. PROMISe trial: a pilot, randomized, placebocontrolled trial of magnetic resonance guided focused ultrasound for uterine fibroids. Fertil Steril 2016;105:773 - 780 http://www.sciencedirect.com/science/article/pii/ S0015028215020907

8. Pron G. Magnetic Resonance-Guided High-Intensity Focused Ultrasound (MRgHIFU) Treatment of Symptomatic Uterine Fibroids: An Evidence-Based Analysis. Ontario Health Technology Assessment Series; Vol. 15: No. 4, pp. 1 - 86, March 2015 http://www.hqontario.ca/evidence/publications-andohtac-recommendations/ontario-health-technology-assessment-series/mr-guided-hifu

9. She WH, TT Cheung, Caroline R Jenkins, Michael G Irwin. Clinical applications of high-intensity focused ultrasound. Hong Kong Med J 2016; 22: Epub. DOI: 10.12809/ hkmj154755 
10. Cheung VYT, Lam TPW, Jenkins CR, Cheung GKI, Chan SSY, Choi WK. Ovarian Reserve After Ultrasound-Guided High-Intensity Focused Ultrasound for Uterine Fibroids: Preliminary Experience. J Obstet Gynaecol Can 2016; 38: 357 - 361 http://dx.doi.org/10.1016/j.jogc.2016.02.006

Conflict of Interest

The authors declare that they have no conflict of interest.
Published simultaneously

Published simultaneously in Geburtshilfe und Frauenheilkunde 6-2017: Geburtshilfe Frauenheilkd 2017; DOI: 10.1055/s-0043-106257 